\title{
Rectal Carcinoma
}

National Cancer Institute

\section{Source}

National Cancer Institute. Rectal Carcinoma. NCI Thesaurus. Code C9382.

A malignant epithelial neoplasm that arises from the rectum and invades through the muscularis mucosa into the submucosa. The vast majority are adenocarcinomas. 